\title{
Obtención, purificación y caracterización de anticuerpos policlonales IgY desarrollados en gallina, dirigidos contra aislamientos colombianos de Giardia duodenalis
}

Dabeiba Adriana García ", Rubén Santiago Nicholls ${ }^{1}$, Adriana Arévalo ${ }^{1}$, Orlando Torres ${ }^{2}$, Sofía Duque ${ }^{1}$

${ }^{1}$ Grupo de Parasitología, Instituto Nacional de Salud, Bogotá, D.C., Colombia.

2 Departamento de Microbiología, Pontificia Universidad Javeriana, Bogotá, D.C., Colombia

Introducción. El desarrollo de anticuerpos policlonales requiere de animales de laboratorio, generalmente, el conejo, que deben sangrarse para su obtención. Como alternativa, se han utilizado las gallinas.

Objetivo. Desarrollar anticuerpos policlonales IgY anti-Giardia duodenalis y evaluar diferentes métodos para su purificación a partir de yema de huevo.

Materiales y métodos. Se inmunizaron tres gallinas intramuscularmente con trofozoítos del parásito: las inmunizaciones se realizaron a los 0, 15, 30, 45, 60, 90 y 120 días. Se recolectaron huevos en cada etapa de la inmunización y se purificó la lgY por deslipidación (D) y precipitación (P) mediante cinco protocolos diferentes: M1: (P: sulfato de amonio/D: dextrán sulfato-cloruro de calcio), M2: (D: dextrán sulfato-cloruro de calcio/P: sulfato de amonio), M3: (D: cloroformo/ P: sulfato de amonio 50\%), M4: (D: solución A/P:solución B) y M5: (D: cloroformo/P: sulfato de amonio 30\%). Se realizó evaluación inmunoquímica de la lgY anti-Giardia duodenalis mediante inmunodifusión, contrainmunoelectroforesis e inmunoelectrotransferencia (Western blot); la pureza de IgY por SDS-PAGE en presencia y ausencia de reductor y la concentración de la inmunoglobulina $(\mathrm{mg} / \mathrm{mL})$ por espectrofotometría y densitometría.

Resultados. La IgY anti-G. duodenalis mediante evaluación inmunoquímica presentó títulos hasta de 1:32. La inmunoglobulina en ausencia de reductor mostró una banda de $180 \mathrm{kd}$ y en su presencia bandas de 30 y $68 \mathrm{kd}$, características de sus cadenas liviana y pesada, respectivamente. Las mayores concentraciones de inmunoglobulina se recuperaron con el método dos (M2), 4,6 mg de IgY por $\mathrm{mL}$ de yema de partida.

Conclusiones. Por su facilidad y economía de producción en gallinas, los anticuerpos policlonales IgY anti-Giardia así obtenidos podrán utilizarse para desarrollar inmunoensayos que detecten el parásito en eluídos de heces.

Palabras clave: Giardia, yema de huevo, anticuerpos antiprotozoarios.

Obtention, purification and characterization of $\lg Y$ polyclonal antibodies, developed in hens, directed against Colombian isolates of Giardia duodenalis

Introduction. The development of polyclonal antibodies requires laboratory animals, as the usually rabbits, which are bled for obtaining the immunoglobulins. Hens are an alternative to developing $\lg Y$ polyclonal antibodies.

Objective. In the current study, hens were used to develop IgY anti-Giardia duodenalis antibodies and to evaluate five protocols for its purification.

Materials and methods. Three hens were immunized intramuscularly immunized with Colombian Giardia duodenalis isolates trophozoites on day 0, 15, 30, 45, 60, 90 and 120. The hen eggs were collected before each immunization, and IgY purified from yolk by delipidation (D) and precipitation (P) using five different protocols: M1: (P: ammonium sulfate/D:dextran sulfate-calcium chloride), M2: (D: dextran sulfate-calcium chloride/P: ammonium sulfate), M3: (D: chloroform/P: ammonium sulfate $50 \%$ ), M4: (D: solution A/P: solution B) and M5: (D: chloroform/P: ammonium sulfate $30 \%$ ). The immunochemistry evaluation of $\lg \mathrm{Y}$ anti-Giardia 
duodenalis was assayed by immunodiffusion, counterimmunoelectrophoresis (CIE) and Western blot. The purity of IgY was assayed by SDS-PAGE under reducing and nonreducing conditions. Immunoglobulin concentration $(\mathrm{mg} / \mathrm{mL})$ was estimated by spectrophotometry and densitometry. Results. IgY anti-Giardia duodenalis by CIE had titres up to 1:32. SDS-PAGE, without 2mercaptoethanol showed a $180 \mathrm{kd}$ band characteristic of the whole to $\lg \mathrm{Y}$ and, with 2mercaptoethanol, two bands of 68 and $30 \mathrm{kd}$, characteristic of its light and heavy chains, respectively. The greatest concentrations of immunoglobulin were recovered by method two (M2), producing $4.6 \mathrm{mg}$ of IgY per $\mathrm{mL}$ of initial egg yolk.

Conclusions. The easy and inexpensive production of $\lg Y$ anti-Giardia duodenalis in hens is an advantage for using it to develop immunoassays that detect the parasite in fecal eluates.

Key words: Giardia, egg yolk, antibodies protozoan.

La giardiosis es una infección intestinal causada por Giardia duodenalis (1) de distribución a nivel mundial. Según la primera encuesta nacional de morbilidad, 1965-1966, la prevalencia en la población colombiana fue de 11,9\% (2), y de 13,7\% en la segunda, 1977-1980 (3). Estudios realizados en niños colombianos de 12 a 59 meses de edad (4) y de 3 a 13 años alojados en asentamientos temporales (5) informaron prevalencias de $21,2 \%$ y de $65 \%$, respectivamente.

La identificación de $G$. duodenalis se realiza tradicionalmente visualizando quistes o trofozoítos del parásito en materia fecal, considerada como la mejor muestra y la de más fácil consecución (6). Sensibilidades mayores a $85 \%$ para la identificación de $G$. duodenalis raramente se logran debido a la excreción intermitente de quistes, fenómeno inherente a la biología del parásito (7). Sin embargo, una alternativa para establecer la presencia de $G$. duodenalis es la detección de antígeno del parásito en heces mediante anticuerpos policlonales anti-Giardia duodenalis (8).

Se han desarrollado anticuerpos policlonales $\lg Y$ contra antígenos específicos de péptidos y proteínas, de virus (rotavirus, enterovirus, picornavirus, arbovirus, paramixovirus, potivirus y adenovirus), de bacterias (Escherichia coli enterotoxigénica y enteropatógena, Brucella abortus) y de algunos parásitos (Echinococcus

\footnotetext{
Correspondencia:

Sofía Duque

Grupo de Parasitología, Instituto Nacional de Salud Avenida Calle 26 No 51-60, Bogotá, D.C., Colombia Teléfono: 2207700, extensión 455; Fax: 2200901 sduque@ins.gov.co
}

Recibido: 18/04/05; aceptado: 03/08/05 granulosus, Naegleria fowleri, Plasmodium falciparum, Sarcocystis gigantae, Toxoplasma gondii y Trypanosoma brucei brucei) (9-13).

La producción de anticuerpos policlonales contra agentes infecciosos requiere de animales de laboratorio, generalmente, conejos, que deben ser sangrados periódicamente para su obtención. Como una alternativa menos invasiva se han utilizado gallinas, debido a que la sangría puede ser reemplazada por la recolección de huevos (14). Además, el uso de las gallinas para la producción de anticuerpos en contraposición al de mamíferos representa reducción en el número de animales porque éstas producen cantidades más altas de anticuerpos (1500 mg de lgY por mes) que los mamíferos pequeños (200 mg de lgG por mes). Las principales clases de anticuerpos en aves son $\lg \mathrm{M}$, IgA e $\lg G$, también llamada IgY. Las aves son una excelente opción para el desarrollo de anticuerpos antimamífero (15-17) y constituyen modelos útiles en la investigación básica de la inmunología, ya que muchas de las funciones de su sistema inmune son similares a las del humano (18).

El propósito de este trabajo fue desarrollar anticuerpos policlonales IgY dirigidos contra aislamientos colombianos de G. duodenalis, hasta la fecha no desarrollados, y evaluar el método de purificación más eficiente para su obtención en términos de reconocimiento de antígeno de Giardia, pureza y concentración $(\mathrm{mg} / \mathrm{mL})$.

\section{Materiales y métodos}

\section{Antígeno de Giardia duodenalis}

Se realizó cultivo masivo de una mezcla de trofozoítos de veinticuatro aislamientos colombianos de G. duodenalis (19) provenientes 
del banco de parásitos del Grupo de Parasitología del Instituto Nacional de Salud (INS). Se centrifugaron los trofozoítos a $1.400 \mathrm{~g}$ a $18^{\circ} \mathrm{C}$ durante 8 minutos, se lavó el sedimento (parásitos) con solución salina fisiológica estéril (SSFE), se resuspendieron en $1 \mathrm{~mL}$ de ésta, se congelaron a $-196^{\circ} \mathrm{C}$, y se descongelaron a $18^{\circ} \mathrm{C}$ mediante vórtex. Se sometieron a disrupción por ultrasonido en un equipo Biosonik II $A^{\circledR}$, a una frecuencia de $20 \mathrm{kHz}$ en tres ciclos de 30 segundos cada uno; se centrifugaron a $1.400 \mathrm{~g}$ a $18^{\circ} \mathrm{C}$ durante 8 minutos y se retuvo el sobrenadante; luego se determinó la concentración de proteínas mediante la técnica de Bradford (20).

\section{Inmunización de gallinas}

Se siguieron las normas internacionales del National Research Council, 1996 (21) y las normas de Cedeño et al., 1994 (22), utilizadas en el Instituto Nacional de Salud para el manejo y mantenimiento de animales. Se utilizaron tres gallinas de la línea Hy Line Brown (23) para el desarrollo de $\lg Y$ anti-G. duodenalis y una gallina de la misma línea como control.

Se utilizó antígeno de trofozoíto de G. duodenalis con una concentración de proteínas de 4,65 mg/ $\mathrm{mL}$. Se tomaron $10,7 \mu \mathrm{L}$ de éste para disolverlos con SSFE hasta completar un volumen de 100 $\mu \mathrm{L}$ y, luego, adicionarles $100 \mu \mathrm{L}$ de adyuvante completo e incompleto de Freund para inóculo inicial e inóculos subsiguientes, respectivamente. Se mezcló el antígeno y los adyuvantes hasta obtener una emulsión homogénea utilizando un vórtex. Se realizó inmunización a tres gallinas en el músculo pectoral a una profundidad de $1 \mathrm{~cm}$ con $200 \mu \mathrm{L}$ del inóculo (que contiene $50 \mu \mathrm{g}$ de antígeno de Giardia) por sitio, y en cinco sitios diferentes de la gallina con la misma concentración y el mismo volumen $(9,24)$. La gallina control se inoculó con $200 \mu \mathrm{L}$ de SSFE. Las inmunizaciones se realizaron a los $0,15,30,45,60,90$ y 120 días $(14,25)$. Se sangró cada gallina en la vena braquial antes de realizar las inmunizaciones y se recolectaron tres huevos; uno el día anterior, otro el día de la inmunización y el último huevo el día posterior a ésta por cada gallina y en cada etapa del esquema de inmunización. Se realizó un pool con las tres yemas de los huevos recolectados
(20 $\mathrm{mL})$ y se utilizaron $4 \mathrm{~mL}$ de éste por cada método de purificación de lgY.

\section{Purificación de la $\lg Y$ a partir de yema de huevo}

Se utilizaron por separado cinco métodos diferentes denominados como M1 (9), M2 (26-28), M3 $(29,30)$, M4 Estuche comercial (EGGstract ${ }^{\circledR}$ IgY purification system - Promega) y M5 (9, 30); todos ellos tuvieron en común el proceso de deslipidación (D) y el de precipitación $(P)$ de la IgY para su purificación.

Método 1 (M1): precipitación (P) con sulfato de amonio y delipidación (D) con dextrán sulfatocloruro de calcio

Se separó la clara de la yema de huevo y ésta se mezcló en proporción $1: 9 \mathrm{v} / \mathrm{v}$ con agua destilada. Se ajustó la mezcla a pH 7,0 , se congeló a $-20^{\circ} \mathrm{C}$ durante 24 horas, se descongeló a $4^{\circ} \mathrm{C}$, se centrifugó a $2.000 \mathrm{~g}$ a $4^{\circ} \mathrm{C}$ durante 20 minutos y se retuvo el sobrenadante. Se precipitó la lgY con sulfato de amonio al $30 \%$, incubado a $18^{\circ} \mathrm{C}$ mediante agitación constante durante 30 minutos. Se centrifugó a $2.000 \mathrm{~g} \mathrm{a} 4^{\circ} \mathrm{C}$ durante 20 minutos y se retuvo el sedimento. Se separaron las lipoproteínas de la $\lg Y$ con dextrán sulfato al $0,2 \%$ incubado a $0^{\circ} \mathrm{C}$ durante 5 minutos, y posteriormente con cloruro de calcio al $0,1 \%$, incubado a la misma temperatura durante 30 minutos. Se centrifugó a $2.000 \mathrm{~g}$ a $4^{\circ} \mathrm{C}$ durante 20 minutos, y el sobrenadante $(\lg Y)$ se dializó contra solución reguladora de fosfatos (PBS).

Método 2 (M2): deslipidación (D) con dextrán sulfato-cloruro de calcio y precipitación $(P)$ con sulfato de amonio

Se separó la clara de la yema de huevo y ésta se mezcló en proporción $1: 9 \mathrm{v} / \mathrm{v}$ con agua destilada. Se ajustó la mezcla a pH 7,0 , se congeló a $-20^{\circ} \mathrm{C}$ durante 24 horas, se descongeló a $4^{\circ} \mathrm{C}$, se centrifugó a $10.000 \mathrm{~g}$ a $4^{\circ} \mathrm{C}$ durante 20 minutos y se retuvo el sobrenadante. Se separaron de la IgY las lipoproteínas con dextrán sulfato al 10\% incubando a $0^{\circ} \mathrm{C}$ durante 5 minutos $\mathrm{y}$, posteriormente, con cloruro de calcio al $11,1 \%$, incubando a la misma temperatura durante 30 minutos. Se centrifugó a $2.000 \mathrm{ga} 4^{\circ} \mathrm{C}$ durante 20 minutos, se retuvo el sobrenadante y se precipitó 
la IgY con sulfato de amonio al $30 \%$, incubando a $18^{\circ} \mathrm{C}$ mediante agitación constante durante 30 minutos. Se centrifugó a $2.000 \mathrm{~g} \mathrm{a} 4^{\circ} \mathrm{C}$ durante 20 minutos, se retuvo el sedimento ( $\lg \mathrm{Y})$, éste se disolvió con PBS en dilución 1:20, y se dializó contra solución reguladora de fosfatos.

Método 3 (M3): deslipidación (D) con cloroformo y precipitación $(P)$ con sulfato de amonio al $50 \%$

Se separó la clara de la yema del huevo. Se separaron los lípidos, mezclando 2 partes de la yema con 3 partes de una solución que contenía $3: 1 \mathrm{v} / \mathrm{v}$ de PBS y cloroformo. Se incubó la mezcla a $18^{\circ} \mathrm{C}$ mediante agitación constante durante 15 minutos, se centrifugó a $3.000 \mathrm{~g}$ a $4^{\circ} \mathrm{C}$ durante 20 minutos y se retuvo el sobrenadante. Se precipitó la IgY con sulfato de amonio al $50 \%$, incubado a $4^{\circ} \mathrm{C}$ mediante agitación constante durante 18 horas, se centrifugó a $3.000 \mathrm{~g}$ a $4^{\circ} \mathrm{C}$ durante 20 minutos, se retuvo el sedimento ( $\lg Y)$, éste se disolvió con $1 \mathrm{~mL}$ de PBS, y se dializó contra solución reguladora de fosfatos.

Método 4 (M4): estuche comercial (EGGstract ${ }^{8}$ IgY purification system - Promega)

Se separó la clara de la yema del huevo. Se separaron los lípidos, mezclando 1 parte de la yema con 3 partes de solución A, se incubó la mezcla a $18^{\circ} \mathrm{C}$ mediante agitación constante durante 5 minutos, se centrifugó a $10.000 \mathrm{~g}$ a $4^{\circ} \mathrm{C}$ durante 10 minutos y se retuvo el sobrenadante. Se precipitó la IgY con solución $B$ en proporción $3: 1 \mathrm{v} / \mathrm{v}$, incubando a $18^{\circ} \mathrm{C}$ durante 5 minutos, se centrifugó a $10.000 \mathrm{~g}$ a $4^{\circ} \mathrm{C}$ durante 10 minutos, se retuvo el sedimento ( $\lg Y)$, y éste se disolvió con PBS en un volumen igual de la yema al inicial.

Método 5 (M5): deslipidación (D) con cloroformo y precipitación $(P)$ con sulfato de amonio al $30 \%$

Se separó la clara de la yema del huevo. Se separaron los lípidos, mezclando 2 partes de la yema con 3 partes de una solución que contenía $3: 1 \mathrm{v} / \mathrm{v}$ de PBS y cloroformo. Se incubó la mezcla a $18^{\circ} \mathrm{C}$ mediante agitación constante durante 15 minutos, se centrifugó a $3.000 \mathrm{ga} 4^{\circ} \mathrm{C}$ durante 20 minutos y se retuvo el sobrenadante. Se precipitó la $\lg Y$ con sulfato de amonio al $30 \%$, incubando a $4^{\circ} \mathrm{C}$ mediante agitación constante durante 18 horas, se centrifugó a $3.000 \mathrm{~g}$ a $4^{\circ} \mathrm{C}$ durante 20 minutos, se retuvo el sedimento ( $\lg Y)$, éste se disolvió con $1 \mathrm{~mL}$ de PBS, y se dializó contra solución reguladora de fosfatos.

\section{Evaluación inmunoquímica de la $\lg Y$}

Se determinó mediante inmunodifusión (ID), contrainmunoelectroforesis (CIE) e inmunoelectrotransferencia (Western blot).

\section{Inmunodifusión}

Se elaboraron dos geles de agarosa al 1,3\%. EI primer gel con solución salina estéril (SSE) 0,15 M para confrontar antígeno de Giardia con $\lg Y$ anti-Giardia presente en el suero de gallina, y el segundo gel con 1,5 M de SSE para dirigir IgY anti-parásito purificada a partir de yema de huevo contra antígeno del parásito. Se eliminaron las bandas inespecíficas con citrato de sodio al $5 \%$ y a las 72 horas se colorearon las bandas correspondientes a la unión antígeno-anticuerpo con azul de Coomassie $(28,31)$.

\section{Contrainmunoelectroforesis}

Se preparó un gel de agarosa al 1,3\% (Sigma tipo $\mathrm{IV}$ ()) con solución reguladora de acetato de sodio - ácido acético pH 5,6. Se realizaron diluciones seriadas al medio de la lgY anti-parásito, que fueron confrontadas con el antígeno de trofozoíto de G. duodenalis mediante CIE a 51 voltios, a una temperatura de $4^{\circ} \mathrm{C}$ durante 3 horas, para determinar la dilución máxima a la cual precipita el complejo. Se eliminaron las bandas inespecíficas con citrato de sodio al $5 \%$ y se colorearon con azul de Coomassie (32).

\section{Inmunoelectro transferencia (Western blot)}

Se realizó mediante el procedimiento descrito por Laemmli (33) y Towbin et al. (34). Se utilizó antígeno de trofozoítos de $G$. duodenalis con una concentración de $(0,8 \mathrm{mg} / \mathrm{mL})$. Se dispensaron $28 \mu \mathrm{g}$ de antígeno en el carril y se separaron las proteínas mediante SDS-PAGE (12,5\%) con y sin el agente reductor 2-mercaptoetanol (2-ME) y, luego, se transfirieron a una membrana de nitrocelulosa (MNC) mediante Western blot a una temperatura de $4^{\circ} \mathrm{C}$, con una corriente de $200 \mathrm{~mA}$ y 130 voltios durante 2 horas. Se verificó la transferencia de proteínas con rojo Ponceau $\mathrm{S}$. Se bloqueó la MNC con leche descremada/PBS- 
Tween 20 al $0,1 \%$ (PBS-T) a $18^{\circ} \mathrm{C}$ durante una hora.

Se confrontaron las proteínas de G. duodenalis presentes en la MNC con IgY anti-parásito (1:400) de las gallinas inmunizadas y de la gallina control independientemente, incubando a $18^{\circ} \mathrm{C}$ durante 18 horas, tiempo después del cual se adicionó anti-IgY unida a fosfatasa alcalina (Promega $\AA$ ) en dilución 1:10.000. Para el reconocimiento de antígenos de trofozoíto de $G$. duodenalis por la $\lg Y$ anti-parásito purificada a partir de yema de huevo se adicionó 5-bromo 4-cloro 3-indol fosfato (BCIP) y azul de nitrotetrazolio (NBT).

\section{Determinación de la pureza de la lgY}

Se determinó la pureza de IgY mediante SDSPAGE $(26,27,35-39)$. Se elaboraron el gel concentrador de poliacrilamida $(5 \%)$ y los geles separadores al $7,5 \%$ sin $2-\mathrm{ME}$ y al $12,5 \%$ con 2 ME. El marcador de peso molecular, la albúmina sérica bovina (BSA) $(1 \mathrm{mg} / \mathrm{mL})$ y la lgY (1:10) se sometieron a electroforesis bajo las siguientes condiciones: temperatura, $18^{\circ} \mathrm{C}$; amperaje, $35 \mathrm{~mA}$; voltaje, 75 voltios; duración, 45 minutos, Los geles obtenidos se colorearon con azul de Coomasie. Concentración $(\mathrm{mg} / \mathrm{mL})$ y porcentaje (\%) de
recuperación de la $\lg \mathrm{Y}$

La concentración de $\lg Y$ se determinó mediante espectrofotometría y densitometría y el porcentaje de recuperación por esta última, como se describe a continuación.

\section{Espectrofotometría}

Se estableció, por triplicado, el valor de la densidad óptica de la lgY (1:10) a una longitud de onda de $280 \mathrm{~nm}$ con un espectrofotómetro (Beckman modelo DU 640) (40). Se determinó la concentración en $\mathrm{mg} / \mathrm{mL}$ de la lgY promediando los 3 valores de densidad óptica, multiplicando el promedio por el factor de dilución y dividiendo este producto por el coeficiente de extinción de la lgY disuelta en PBS 0,01M, que es de 13,2 $(40,41)$.

\section{Densitometría}

Se digitalizaron los geles procesados mediante SDS-PAGE que contenían tanto la lgY $180 \mathrm{kd}$ como sus cadenas liviana y pesada, de 30 y 68 kd, respectivamente. Se utilizó el programa para procesamiento y análisis de imágenes «ImageJ», (http://rsbweb.nih.gov/ij/); se determinó la intensidad relativa de color de la banda patrón de BSA, y las correspondientes a la lgY total (180 $\mathrm{kd}$ ) y sus cadenas pesada y liviana (68 y $30 \mathrm{kd}$ ), así como las de las áreas contiguas a cada una de ellas (ruido de fondo). La diferencia de la intensidad relativa de estas bandas con la del ruido de fondo determinó el valor neto de la intensidad de color del patrón y de la lgY. La concentración de la IgY se definió como el cociente de la intensidad relativa neta de la IgY y la intensidad relativa neta del patrón. Se realizó control de calidad a la determinación de la concentración $(\mathrm{mg} / \mathrm{mL})$ de la $\mathrm{lg} Y$ recuperada por cada uno de los métodos de purificación utilizados, y por el que presentase el mayor título en la evaluación inmunoquímica, sometiéndola a SDS-PAGE.

Se determinó por separado el porcentaje de recuperación de la lgY obtenida en cada uno de los métodos de purificación (M1-M5), dividiendo el valor de la intensidad relativa de la inmunoglobulina entre la suma de las intensidades relativas de todas las bandas obtenidas por SDS-PAGE y multiplicando por 100 los valores obtenidos.

\section{Resultados}

\section{Evaluación inmunoquímica de $\lg Y$ anti- Giardia duodenalis}

La IgY anti-Giardia duodenalis en suero y purificada de yema de huevo se unió inmunoquímicamente con el antígeno del parásito en los días $30,45,60,90$ y 120 posinmunización sólo en las yemas de huevos obtenidos de las gallinas inmunizadas, y no se hizo ninguna unión inmunoquímica en la gallina control (cuadro 1).

La máxima dilución detectada de unión entre antígeno (trofozoíto del parásito) y anticuerpo (IgY anti-G.duodenalis) fue de 1:32 al día 30 posinmunización utilizando el método 2 de purificación (cuadro 1).

La IgY purificada a partir de yema de huevo utilizando el método 2 reconoció, en condición no reductora, los antígenos de trofozoíto de $G$. duodenalis de pesos moleculares de 24, 56, 64, 
Cuadro 1. Evaluación inmunoquímica de IgY anti-Giardia duodenalis en suero y yema de huevo en la gallina inmunizada No. 1 en diferentes días de inmunización y según los diferentes métodos utilizados para la purificación de la lgY.

\begin{tabular}{|c|c|c|c|c|c|c|c|c|c|c|c|c|}
\hline \multirow{3}{*}{$\begin{array}{l}\text { Inmunización } \\
\text { (Día) }\end{array}$} & & & \multicolumn{10}{|c|}{ IgY a partir de yema de huevo } \\
\hline & \multicolumn{2}{|c|}{ IgY suero } & \multicolumn{2}{|c|}{ Método 1} & \multicolumn{2}{|c|}{ Método 2} & \multicolumn{2}{|c|}{ Método 3} & \multicolumn{2}{|c|}{ Método 4} & \multicolumn{2}{|c|}{ Método 5} \\
\hline & ID & CIE & ID & CIE & ID & CIE & ID & CIE & ID & CIE & ID & CIE \\
\hline 0 & $(-)$ & $(-)$ & $(-)$ & $(-)$ & $(-)$ & $(-)$ & $(-)$ & $(-)$ & $(-)$ & $(-)$ & $(-)$ & $(-)$ \\
\hline 15 & $(-)$ & $(-)$ & $(-)$ & $(-)$ & $(-)$ & $(-)$ & $(-)$ & $(-)$ & $(-)$ & $(-)$ & $(-)$ & $(-)$ \\
\hline 30 & $(+)$ & $(+)$ & $(+)$ & $1: 4$ & $(+)$ & $1: 32$ & $(-)$ & SD & $(-)$ & $1: 16$ & $(-)$ & $(-)$ \\
\hline 45 & $(+)$ & $(+)$ & $(+)$ & SD & $(+)$ & SD & $(-)$ & SD & $(-)$ & $1: 2$ & $(-)$ & SD \\
\hline 60 & $(+)$ & $(+)$ & $(+)$ & $1: 4$ & $(+)$ & $1: 8$ & $(-)$ & SD & $(-)$ & $1: 8$ & $(-)$ & SD \\
\hline 90 & $(-)$ & $(+)$ & $(-)$ & $1: 4$ & $(-)$ & $1: 2$ & $(-)$ & $1: 4$ & $(-)$ & $1: 4$ & $(-)$ & $(-)$ \\
\hline 120 & $(-)$ & $(-)$ & $(-)$ & $(-)$ & $(-)$ & $1: 2$ & $(-)$ & SD & $(-)$ & $1: 8$ & $(-)$ & $(-)$ \\
\hline
\end{tabular}

ID: inmunodifusión; CIE: contrainmunoelectroforesis; SD: sin diluir; (-): negativo.

Gallina control: todos los resultados de la evaluación inmunoquímca de la lgY purificada a partir de yema de huevo fueron negativos.

$67,74,86,165$, y $170 \mathrm{kd}$, y en presencia de 2 ME, los antígenos de $25,35,43,49,52,60,65$, $72,78,82,99$ y $170 \mathrm{kd}$ (figura 1).

\section{Pureza de la $\lg Y$}

\section{En condición no reductora}

La banda de $180 \mathrm{kd}$, correspondiente al peso molecular de la $\lg \mathrm{Y}$, se obtuvo utilizando todos los métodos de purificación (M1-M5); también se obtuvieron bandas adicionales con pesos moleculares entre 62 y $98 \mathrm{kd}$ (figura 2A).

\section{En condición reductora}

Las cadenas liviana y pesada de la $\lg \mathrm{Y}$, con pesos moleculares de 30 y $68 \mathrm{kd}$, se lograron purificando la $\lg Y$ mediante los 5 métodos empleados, con los cuales se obtuvo también una banda adicional de $48 \mathrm{kd}$. Bandas adicionales de 40, 170 y $180 \mathrm{kd}$ se obtuvieron utilizando los métodos M1, M2 y M5, y una banda adicional de 56 kd sólo con M3 (figura 2B).

\section{Concentración de la $\lg Y$}

\section{Espectrofotometría}

La concentración de $\lg Y$ en el día 0 , día preinmunización, fue mayor a la del día 15 posinmunización, día a partir del cual la concentración de $\lg Y$ incrementó hasta el día 45 y disminuyó paulatinamente hasta el día 120, con picos máximos en los días 30,45 y 60 posinmunización. Las concentraciones de

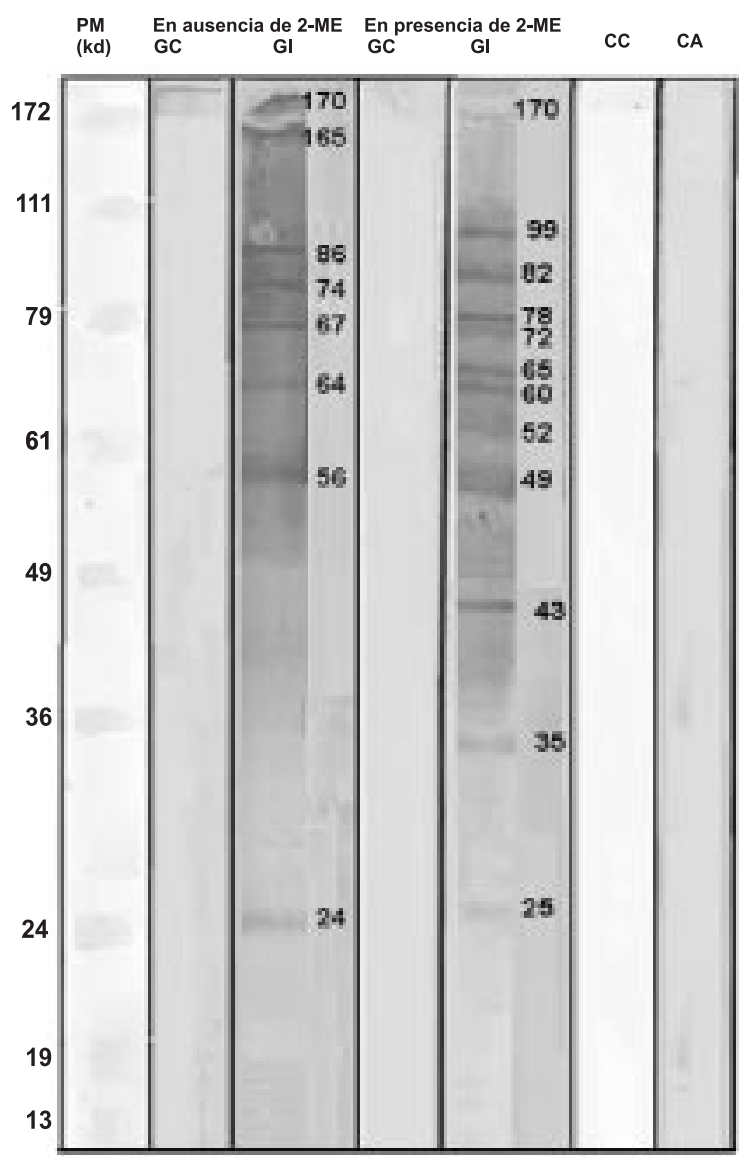

Figura 1. Identificación mediante inmunoelectrotransferencia de antígenos de trofozoíto de Giardia duodenalis por anticuerpos IgY presentes en yema de huevo mediante el método de purificación 2 en la gallina No 1 . 


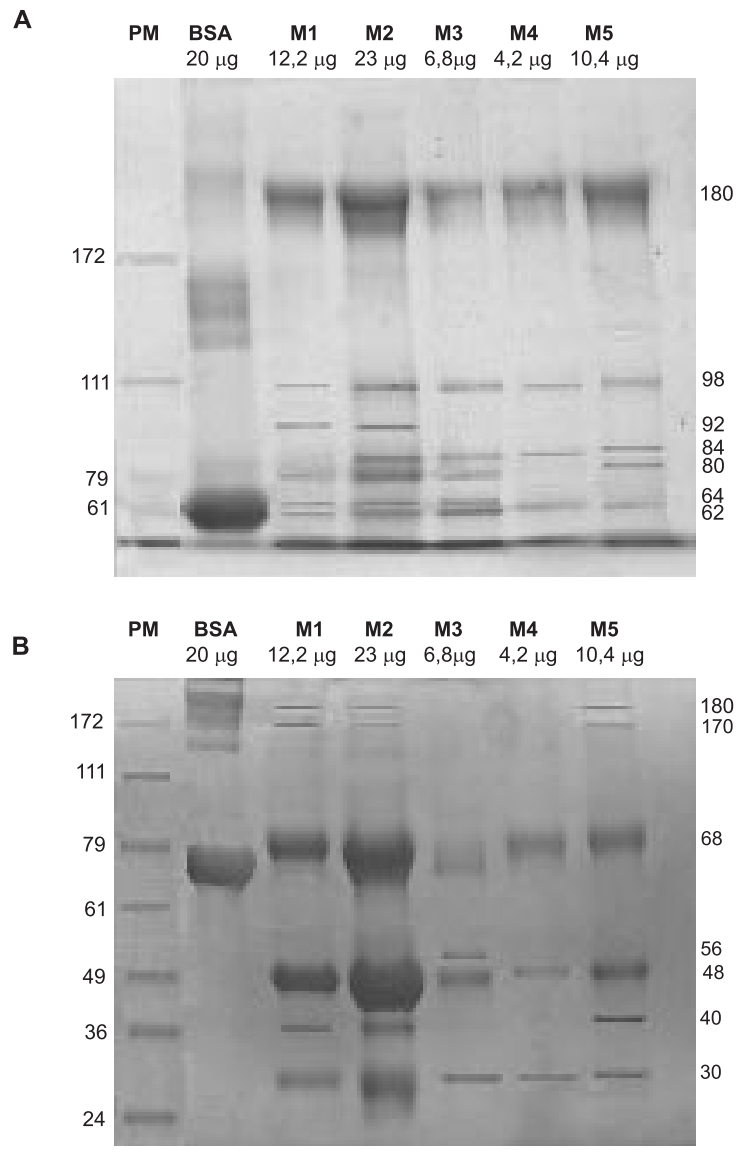

PM: Marcador de peso molecular

Figura 2. Determinación de la pureza de $\lg Y$ obtenida mediante los cinco métodos de purificación a partir de yema de huevo en la gallina No 1. A. SDS-PAGE en condición no reductora. B: SDS-PAGE en condición reductora.

inmunoglobulina variaron entre los ejemplares y los métodos de purificación utilizados (cuadro 2).

\section{Densitometría}

La concentración de lgY total recuperada por cada uno de los métodos de purificación se describen en el cuadro 2.

\section{Control de calidad de la determinación de la concentración $(\mathrm{mg} / \mathrm{mL})$ de la $\lg Y$}

La máxima unión antígeno de Giardia e lgY antiparásito fue obtenida en el día 30 del esquema de inmunización y determinada por $\mathrm{CIE}$, presentando un título de 1:32 (cuadro 1); las concentraciones de recuperadas por cada uno de los métodos de purificación, en condición no reductora y reductora, se mencionan en el cuadro 3.

\section{Porcentaje de recuperación de la lgY mediante los cinco métodos de purificación utilizados}

La IgY anti-G. duodenalis con mayor unión al antígeno del parásito fue desarrollada por la gallina inmunizada No. 1 en el día 30 de inmunización con título de 1:32. El porcentaje de lgY recuperada con respecto a los contaminantes presentes en los dializados por cada uno de los métodos de purificación utilizados se especifican en el cuadro 3.

\section{Discusión}

Anteriormente se han desarrollado $\lg Y$ antiagentes infecciosos (9) utilizando diferentes protocolos. Sin embargo, la comparación entre protocolos es difícil por la variedad de antígenos y las concentraciones utilizadas, así como también por las vías de inoculación y frecuencias empleadas en las inmunizaciones. Durante el desarrollo de la lgY anti-aislamientos colombianos de Giardia, el presente estudio mantuvo constante el adyuvante, la calidad y la concentración del antígeno, el volumen de inóculo, el sitio y la frecuencia de inoculación, el número e intervalo de inmunizaciones y la edad de los ejemplares, que son los parámetros requeridos para tal fin.

El presente trabajo utilizó por sitio de inoculación, una concentración de $50 \mu \mathrm{g}$ de antígeno de trofozoíto de $G$. duodenalis en $0,2 \mathrm{~mL}$ de adyuvante completo e incompleto de Freund para inóculo inicial y refuerzos, respectivamente. La concentración de antígeno y volumen utilizados se encuentran dentro de los rangos de $10 \mathrm{ng}$ a 1 $\mathrm{mg}$ (14) y de $0,1 \mathrm{~mL}$ a $0,25 \mathrm{~mL}$, respectivamente $(14,42)$, los cuales son los recomendados para la inmunización de gallinas. La IgY desarrollada en el estudio corresponde a IgY anti-Giardia, lo que fue comprobado por la unión específica del antígeno al parásito, y visualizada en la evaluación inmunoquímica por ID, CIE y WB.

Se ha demostrado en gallinas que, después de la primera inmunización, los títulos lgY anti-bacterias alcanzan un pico en la semana 4 en suero, y entre las semanas 6 a 8 en yema de huevo, que luego descienden en la semana 12. Sin embargo, los 
Cuadro 2. Concentración de $\lg Y$ a partir de la yema de huevo determinada mediante espectrofotometría y densitometría.

\begin{tabular}{|c|c|c|c|c|}
\hline \multicolumn{5}{|c|}{ mg de lgY por mL de yema de partida } \\
\hline \multirow{3}{*}{$\begin{array}{l}\text { Inmunización } \\
\text { (Día) }\end{array}$} & \multicolumn{2}{|c|}{ Espectrofotometría } & \multicolumn{2}{|c|}{ Densitometría } \\
\hline & \multicolumn{4}{|c|}{$\begin{array}{l}\text { Método de purificación } 1 \text { (M1) (SA/DS-CC) } \\
\text { Precipitación (P): Sulfato de amonio/ } \\
\text { Delipidación (D): Dextran Sulfato-Cloruro de Calcio }\end{array}$} \\
\hline & $\begin{array}{l}\text { Gallina } \\
\text { inmunizada }\end{array}$ & $\begin{array}{l}\text { Gallina } \\
\text { control }\end{array}$ & $\begin{array}{c}\text { Gallina } \\
\text { inmunizada }\end{array}$ & $\begin{array}{l}\text { Gallina } \\
\text { control }\end{array}$ \\
\hline 0 & 4,3 & 2,8 & 8,0 & 3,6 \\
\hline 15 & 1,8 & 1,2 & 7,3 & 2,1 \\
\hline 30 & 3,8 & 6,3 & 4,9 & 4,3 \\
\hline 45 & 9,6 & 5,6 & 7,1 & 3,5 \\
\hline 60 & 2,8 & 4,6 & 5,7 & 1,7 \\
\hline 90 & 2,6 & 2,4 & 5,1 & 1,3 \\
\hline \multirow[t]{2}{*}{120} & 1,8 & 2,8 & 5,4 & 1,6 \\
\hline & \multicolumn{4}{|c|}{$\begin{array}{l}\text { Método de purificación } 2 \text { (M2) (DS-CC/SA) } \\
\text { D: Dextran Sulfato-Cloruro de Calcio/ } \\
\text { P: Sulfato de amonio }\end{array}$} \\
\hline 0 & 2,4 & 2,8 & 2,6 & 3,0 \\
\hline 15 & 1,1 & 1,9 & 4,3 & 2,3 \\
\hline 30 & 7,2 & 2,9 & 5,1 & 1,6 \\
\hline 45 & 3,8 & 1,3 & 3,8 & 2,1 \\
\hline 60 & 3,8 & 2,5 & 4,4 & 1,9 \\
\hline 90 & 4,4 & 2,2 & 3,5 & 1,8 \\
\hline \multirow[t]{2}{*}{120} & 3,7 & 4,4 & 3,3 & 1,3 \\
\hline & \multicolumn{4}{|c|}{$\begin{array}{l}\text { Método de purificación } 3 \text { (M3) (C/SA 50\%) } \\
\text { D: Cloroformo/P: Sulfato de amonio 50\% }\end{array}$} \\
\hline 0 & 6,3 & 5,1 & 3,1 & 1,8 \\
\hline 15 & 4,1 & 4,6 & 3,4 & 1,6 \\
\hline 30 & 2,1 & 3,4 & 2,1 & 1,9 \\
\hline 45 & 2,8 & 1,4 & 2,9 & 1,3 \\
\hline 60 & 6,7 & 5,6 & 4,8 & 1,1 \\
\hline 90 & 5,6 & 5,8 & 3,9 & 0,7 \\
\hline \multirow{2}{*}{120} & 4,8 & 6,6 & 2,9 & 0,6 \\
\hline & \multicolumn{4}{|c|}{$\begin{array}{l}\text { Método de purificación } 4 \text { (M4) (A/B) } \\
\text { D: Solución A/P: Solución B }\end{array}$} \\
\hline 0 & 0,6 & 0,3 & 2,2 & 0,5 \\
\hline 15 & 0,4 & 0,5 & 1,6 & 0,8 \\
\hline 30 & 1,3 & 0,3 & 3,5 & 1,0 \\
\hline 45 & 1,1 & 0,9 & 3,4 & 0,9 \\
\hline 60 & 3,3 & 3,3 & 5,5 & 1,3 \\
\hline 90 & 4,4 & 5,1 & 5,4 & 2,0 \\
\hline \multirow{2}{*}{120} & 3,6 & & & 1,7 \\
\hline & \multicolumn{4}{|c|}{$\begin{array}{l}\text { Método de purificación } 5 \text { (M5) (C/SA 30\%) } \\
\text { D: Solución A/P: Solución B }\end{array}$} \\
\hline 0 & 3,3 & 2,4 & 2,8 & 1,9 \\
\hline 15 & 2,9 & 1,6 & 2,8 & 1,7 \\
\hline 30 & 3,3 & 2,9 & 4,1 & 2,3 \\
\hline 45 & 4,4 & 1,1 & 3,9 & 1,3 \\
\hline 60 & 3,4 & 3,4 & 4,2 & 2,3 \\
\hline 90 & 4,9 & 3,6 & 2,6 & 2,4 \\
\hline 120 & 2,6 & 3,9 & 2,9 & 2,5 \\
\hline
\end{tabular}


Cuadro 3. Concentraciones y porcentajes de recuperación de la $\lg Y$ a partir de yema de huevo, utilizando diferentes métodos de purificación y determinados mediante densitometría.

\begin{tabular}{|c|c|c|c|c|c|c|}
\hline \multicolumn{7}{|c|}{$\lg Y$} \\
\hline \multirow{2}{*}{$\begin{array}{l}\text { Método de } \\
\text { purificación }\end{array}$} & \multicolumn{3}{|c|}{$\begin{array}{l}\text { Concentración } \\
(\mathrm{mg} / \mathrm{mL})\end{array}$} & \multirow[b]{2}{*}{$\begin{array}{l}\text { Mililitros } \\
\text { recuperados }\end{array}$} & \multirow{2}{*}{$\begin{array}{c}\text { mg de } \lg Y \\
\text { por } \mathrm{mL} \text { de } \\
\text { yema de partida }\end{array}$} & \multirow{2}{*}{$\begin{array}{c}\text { Recuperación } \\
(\%)\end{array}$} \\
\hline & $\begin{array}{l}\text { Cadena } \\
\text { pesada }\end{array}$ & $\begin{array}{l}\text { Cadena } \\
\text { ligera }\end{array}$ & $\begin{array}{l}\text { Cadena } \\
\text { completa }\end{array}$ & & & \\
\hline M1 & 12,7 & 7,5 & 4,5 & 2,5 & 2,8 & 63 \\
\hline M2 & 22,7 & 12,2 & 7,4 & 2,5 & 4,6 & 70 \\
\hline M3 & 5,1 & 1,7 & 2,8 & 2,5 & 1,7 & 62 \\
\hline M4 & 7,4 & 4,5 & 3,9 & 2,5 & 2,4 & 65 \\
\hline M5 & 11,7 & 6,8 & 5,5 & 2,5 & 3,4 & 68 \\
\hline
\end{tabular}

títulos de la inmunoglobulina pueden aumentar reinmunizando las gallinas en la semana 14 (43). En este estudio se alcanzaron títulos de lgY antiG. duodenalis determinados mediante CIE sin diluir hasta una dilución máxima de 1:32 en la semana 4, lo que corresponde a la respuesta del segundo refuerzo de inmunización.

Los esquemas de inmunización con largos períodos de tiempo y con refuerzos repetidos incrementan el desarrollo de anticuerpos afines al antígeno inoculado, aunque también pueden inducir la producción de anticuerpos específicos contra otras moléculas presentes en la solución diluyente del antígeno (44). Por ello, de acuerdo con los resultados del estudio, se sugiere inmunizar a las gallinas con antígeno de trofozoíto de $G$. duodenalis hasta la semana 8, aplicando cuatro inmunizaciones con intervalo de dos semanas entre cada una de ellas.

El desarrollo de anticuerpos ante el estímulo de un antígeno es inherente de cada animal inmunizado (45). Generalmente, los animales utilizados para la producción de anticuerpos policlonales son ejemplares exocriados porque éstos tienen un amplio rango de proteínas de clase II del complejo mayor de histocompatibilidad (MHC II), que generan una respuesta inmune diferente y específica en cada animal (29). En 1996, Schade et al. (14) informaron que, después de una inmunización, entre $10 \%$ y $15 \%$ de gallinas exocriadas pueden no desarrollar anticuerpos contra el agente etiológico con las cuales fueron inmunizadas, o en otros casos, generar una producción de anticuerpos muy bajos ante el estímulo de un antígeno. En el estudio se inmunizaron tres ejemplares exocriados, obteniéndose una producción de anticuerpos policlonales IgY anti-G. duodenalis en todas las posinmunizaciones en dos de los ejemplares, la gallina No.1 y la gallina No.3. En cambio la gallina No.4 desarrolló IgY anti-G. duodenalis tan sólo en las dos primeras inmunizaciones, demostrándose una menor producción de anticuerpos policlonales en relación a las otras dos inmunizaciones con el mismo volumen y la misma concentración de antígeno. Por ello, para garantizar el desarrollo de IgY anti-G. duodenalis siguiendo las pautas aquí establecidas, se recomienda inmunizar como mínimo dos ejemplares.

La recuperación de IgY no requiere de procedimientos invasivos como la sangría que se realiza en mamíferos, pues la postura de huevos es un proceso natural de las aves. Las gallinas pueden ser consideradas como fuente eficiente y una alternativa ideal para el desarrollo de lgY antiG. duodenalis.

La IgY total obtenida en el estudio fue purificada a partir de yema de huevo por eliminación de las lipoproteínas (delipidación) y recuperada mediante precipitación, siguiendo los protocolos usualmente utilizados para tal fin (9,26-30). Existen diferencias en los procesos físicos y en los reactivos utilizados para delipidar y precipitar la lgY. La deslipidación se ha realizado mediante métodos físicos como congelación/descongelación y ultracentrifugación, o mediante métodos químicos que usan gomas naturales como el xanthan, agua 
destilada acidificada o dextran sulfato/cloruro de sodio, azul dextran, cloroformo, polietilenglicol (PEG) 6000, PEG 8000 y propanol/acetona, o mediante cromatografía de intercambio iónico $(9$, 24,26-28,35,36,38,39,43,46-53).

La IgY contra parásitos como Toxoplasma gondii, Naegleria fowleri, Trypanosoma brucei brucei y Plasmodium falciparum ha sido delipidada utilizando PEG 6000, cromatografía de interacción hidrofóbica o filtración en gel, o agua destilada acidificada $(11,12,37,54)$.

Los lípidos son solubles en solventes orgánicos como el cloroformo, el éter, la acetona o el propanol, lo cual permite usarlos para removerlos (13), y las lipoproteínas forman complejos insolubles con compuestos polianiónicos, particularmente polisacáridos sulfatados como el dextrán sulfato en presencia de cationes divalentes como el calcio, el magnesio o el manganeso (Baykeev R, Muhamadiev F, Vasiliev G. Influence of the organic solvents on to the dynamic heterogeneity of lipids in the structure of biological membranes. Proceedings of the $15^{\text {th }}$ European experimental NMR conference: 2000 Jun 12-17; University of Leipzig, Germany). La deslipidación de lgY en la fase acuosa de la yema de huevo, utilizando cloroformo como se realizó en el estudio, permitió recuperar $3,4 \mathrm{mg}$ de la inmunoglobulina por $\mathrm{mL}$ de yema de partida, siendo esta concentración menor a la obtenida utilizando dextran sulfato/cloruro de calcio, que fue de 4,6 mg de lgY por $\mathrm{mL}$ de yema de partida. La IgY libre de lípidos ha sido recuperada mediante ultracentrifugación, filtración en gel y cromatografía de intercambio iónico (27), y por cromatografía de afinidad (52), o mediante precipitación con PEG o con sulfato de sodio o sulfato de amonio $(27,29)$.

Los resultados obtenidos permitieron inferir que la purificación de $\lg Y$ se puede realizar utilizando cualquiera de los cinco métodos estudiados. Sin embargo, la eficiencia de los métodos analizada en términos de pureza y evidenciada en los geles SDS-PAGE difiere según el método utilizado y a si la IgY se somete o no a agentes reductores como el 2-ME. Así, la pureza de lgY en condición reductora presenta 5 bandas (contaminantes) y en condición no reductora presenta 6 contaminantes, sumados para el conjunto de los métodos. El método 4 (delipidación con solución A/precipitación con solución B) recuperó la lgY con la menor cantidad de contaminantes (tres bandas de 62, 84 y $98 \mathrm{kd}$ ). Estos pesos moleculares son lejanos al de $180 \mathrm{kd}$ correspondiente al de la $\lg Y$ en condición no reductora. Se infiere que estos contaminantes no alteran la naturaleza físicoquímica de la inmunoglobulina.

Separar la yema de la albúmina del huevo garantizó la ausencia de las inmunoglobulinas IgA e lgM en el proceso de purificación de la IgY total como lo habían experimentado Erhard y Schade en el 2001 (47). La unión de antígeno (trofozoíto de Giardia duodenalis) y de anticuerpo (IgY antiparásito) visualizada mediante la formación de bandas de precipitación al utilizar las pruebas inmunoquímicas de inmunodifusión, contrainmunoelectroforesis y Western blot confirmó el desarrollo de $\lg Y$ anti-G. duodenalis de aislados colombianos como respuesta inmune al estímulo de antígeno somático del parásito.

La visualización de la unión antígeno de Giardia e IgY anti-parásito mediante CIE en el día 15, que contrasta con su ausencia en inmunodifusión, puede explicarse en términos de: a) los anticuerpos policlonales IgY anti-parásito presentes en suero y en yema de huevo probablemente estén acompañados de otras moléculas, las cuales podrían interferir con la libre migración de la $\lg Y$, y b) la sensibilidad de las pruebas utilizadas. Así, se conoce que la CIE es diez veces más sensible que la ID para detectar la unión antígeno-anticuerpo $(55,56)$, permitiendo observar la individualidad de la respuesta inmune que cada ser vivo desarrolla ante el reto de un antígeno.

El estudio permite inferir que la utilización de dextrán sulfato/cloruro de calcio en la deslipidación y de sulfato de amonio en la precipitación (método 2) es el mejor para la recuperación de la inmunoglobulina y ésto concuerda con lo observado por Rangel et al. en 1999 (44). En comparación con los otros métodos de purificación, el método 2 es el más eficiente en términos de concentración de la inmunoglobulina 
recuperada, es decir, 4,6 $\mathrm{mg}$ de $\lg Y$ por $\mathrm{mL}$ de yema de partida; de su pureza (70\%), y de su título 1:32, evaluado por la pruebas inmunoquímicas ID, CIE y WB.

Hasta donde se ha tenido acceso a la literatura científica existen muchos trabajos de producción de anticuerpos en gallina, pero de IgY anti-Giardia, y específicamente contra aislamientos colombianos del parásito, no se habían desarrollado con anterioridad. Sólo se habían producido anticuerpos policlonales IgY contra las siguientes especies de parásitos: Echinococcus granulosus, Naegleria fowleri, Plasmodium falciparum, Sarcocystis gigantae, Toxoplasma gondii y Trypanosoma brucei brucei (9-13).

Por su facilidad, economía y rendimiento en la producción, los anticuerpos policlonales lgY antiaislamientos colombianos de Giardia pueden utilizarse para desarrollar inmunoensayos que detecten antígeno del parásito en eluídos de heces humanas o de animales infectados experimentalmente.

\section{Agradecimientos}

Los autores agradecen a Javier Eduardo Gómez Meza, del Grupo Producción y Desarrollo Tecnológico de la Subdirección Industrial del Instituto Nacional de Salud, por su colaboración durante la realización de este trabajo.

\section{Conflicto de intereses}

Los autores declaran no haber incurrido en ninguna situación de conflicto de intereses durante la realización de este trabajo.

\section{Financiación}

Este trabajo fue financiado en su totalidad por el Instituto Nacional de Salud.

\section{Referencias}

1. Adam RD. Biology of Giardia lamblia. Clin Microbiol Rev 2001;14:447-75.

2. Galán R, Agualimpia C, Corredor A, Cáceres E. Parasitismo intestinal - Investigación Nacional de Morbilidad. Bogotá, D.E.: Instituto Nacional para Investigaciones Especiales-INPES; 1969.

3. Corredor A, Arciniegas E, Hernández CA, editores. Parasitismo intestinal. Santa Fe de Bogotá, D.C.: Instituto Nacional de Salud; 2000.
4. Castro de Navarro L, Nicholls S. Deficiencia de hierro, vitamina A y prevalencia de parasitismo intestinal en la población infantil y anemia nutricional en mujeres en edad fértil Colombia 1995-1996. Santafé de Bogotá D.C.: Instituto Nacional de Salud; 1998.

5. Torres E, Gallego ML, Gómez JE. Giardiasis en niños viviendo en asentamientos temporales en Armenia. Infectio 2002;6:89.

6. Duque S, Nicholls RS, Arévalo A, Guerrero R, Montenegro S, James MA. Detection of Giardia duodenalis antigen in human fecal eluates by enzymelinked immunosorbent assay using polyclonal antibodies. Mem Inst Oswaldo Cruz 2002;97:1165-8.

7. Faubert GM, Belosevic M. Animal model for Giardia duodenalis type organisms. En: Meyer EA, editor. Human parasitic diseases. Amsterdam: Elsevier Science Publishers Biomedical División; 1990. p.7790.

8. Ungar BLP, Yolken RH, Nash TE, Quinn TC. Enzymelinked immunosorbent assay for the detection of Giardia lamblia in fecal specimens. J Infect Dis 1984;149:90-7.

9. Schade R, Pfister C, Halatsch R, Henklein P. Policlonal IgY antibodies from chicken egg yolk - an alternative to the production of mammalian IgG type antibodies in rabbits. Altern Lab Anim 1991;19:403-19.

10. Morty RE, Lonsdale-Eccles JD, Mentele R, Auerswald EA, Coetzer THT. Trypanosome-derived oligopeptidase $B$ is released into the plasma of infected rodents, where it persists and retains full catalytic activity. Infect Immun 2001;69:2757-61.

11. Herbst R, Ott C, Jacobs T, Marti T, Marciano-Cabral F, Leippe M. Pore-forming polypeptides of the pathogenic protozoon Naegleria fowleri. J Biol Chem 2002;277:22353-60.

12. Kang X, Szallies A, Rawer M, Echner H, Duszenko M. GPI anchor transamidase of Trypanosoma brucei: in vitro assay of the recombinant protein and VSG anchor exchange. J Cell Sci 2002;115:2529-39.

13. Merckx A, Le Roch K, Nivez MP, Dorin D, Alano P, Gutierrez GJ et al. Identification and initial characterization of three novel cyclin-related proteins of the human malaria parasite Plasmodium falciparum. J Biol Chem 2003;278:39839-50.

14. Schade R, Staak C, Hendriksen C, Erhard M, Hugo $\mathbf{H}$, Koch G, et al. The production of avian (egg yolk) antibodies: IgY. Altern Lab Anim 1996;24:925-34.

15. Erhard ME, Schmidt P, Hofmann A, Stangassinger M, Losch U. Production and purification of mouse IgG subclass specific chicken egg yolk antibodies using a new indirect affinity chromatography method with protein G sepharose. ALTEX 1996;13:66-9.

16. Terzolo HR, Sandoval VE, Caffer MI, Terragno R, Alcain A. Agglutination of hen egg-yolk immunoglobulins 
( $\lg Y)$ against Salmonella enterica, serovar enteritidis. Rev Argent Microbiol 1998;30:84-92.

17. Alarcón CE, Hurtado H, Castellanos J. Anticuerpos aviares: alternativa en producción y diagnóstico. Biomédica 2000;20:338-43.

18. Sharma JM. The structure and function of the avian immune system. Acta Vet Hung 1997;45:229-38.

19. Duque S, Nicholls RS, Arévalo A, Guerrero R. Serodiagnóstico de giardiosis: identificación de inmunoglobulina $\mathrm{G}$ anti-Giardia duodenalis en suero mediante Elisa. Biomédica 2001;21:228-31.

20. Bradford MM. A rapid and sensitive method for the quantitation of microgram quantities of protein utilizing the principle of protein-dye binding. Anal Biochem 1976;72:248-54.

21. National Research Council. Guide for the care and use of laboratory animals. Washington, D.C.:Institute of Laboratory Animal Resourses; 1996.

22. Cedeño D, Lugo L, Muñoz J, Maldonado J. Guía para el uso de animales de experimentación. Santafé de Bogotá, D.C.: Instituto Nacional de Salud; 1994.

23. Lastra IJ, Nuñez R, Enciso A, Gallardo JL, Ramírez R. Importancia de los recursos genéticos pecuarios en la producción animal. Revista Claridades Agropecuarias 2001;91:3-26.

24. Ntakarutimana V, Demedts $P$, Van Sande $M$, Scharpé S. A simple and economical strategy for downstream processing of specific antibodies to human transferrin from egg yolk. J Immunol Methods 1992;153:133-40.

25. Altschuh D, Hennache G, Van Regenmortel MH. Determination of $\lg G$ and $\operatorname{lgM}$ levels in serum by rocket immunoelectrophoresis using yolk antibodies from immunized chickens. J Immunol Methods 1984;69:1-7.

26. Jensenius JC, Andersen I, Hau J, Crone M, Koch C. Eggs: Conveniently packaged antibodies methods for purification of yolk IgG. J Immunol Methods 1981;46:638.

27. Akita EM, Nakai S. Comparison of four purification methods for the production of immunoglobulins from eggs laid by hens immunized with an enterotoxigenic E. coli strain. J Immunol Methods 1993;160:207-14.

28. Jensenius JC, Koch C. Antibodies packaged in eggs In: Johnstone AP, Turner MW, editors. Immunochemistry. 1. A practical approach. Oxford: Oxford University Press; 1997. p.89-104.

29. Harlow E, Lane D. Antibodies: a laboratory manual. New York: Cold Spring Harbor Laboratory Publications; 1988.

30. Svendsen Bollen L, Crowley A, Stodulski G, Hau J. Antibody production in rabbits and chickens immunized with human IgG. A comparison of titre and avidity development in rabbit serum, chicken serum and egg yolk using three different adjuvants. J Immunol Methods 1996;191:113-20.

31. Ouchterlony 0 . Diffusion in gel methods for immunological analysis. Progress Allergy 1958;5:1-78.

32. McKinney KL, Rimler RB. Immunoelectrophoresis employing avian antisera for the detection and quantitation of Pasteurella multocida antigens. J Immunol Methods 1981;43:1-13.

33. Laemmli UK. Cleavage of structural proteins during the assembly of the head of bacteriophage T4. Nature 1970;227:680-5.

34. Towbin H, Staehelin T, Gordon J. Electrophoretic transfer of proteins from polyacrylamide gels to nitrocellulose sheets: procedure and some applications. Proc Natl Acad Sci USA 1979;76:4350-4.

35. Bade H, Stegemann H. Rapid method of extraction of antibodies from hen egg yolk. J Immunol Methods 1984;72:421-6.

36. Song CS, Yu JH, Bai DH, Hester PY, Kim KH. Antibodies to the $\alpha$-subunit of insulin receptor from eggs of immunized hens. J Immunol 1985;135:3354-9.

37. Hassl A, Aspock H. Purification of egg yolk immunoglobulins. A two step procedure using hydrophobic interaction chromatography and gel filtration. J Immunol Methods 1988;110:225-8.

38. Gassman M, Thömmes $P$, Weiser T, Hubscher U. Efficient production of chicken egg yolk antibodies against a conserved mammalian protein. FASEB $\mathrm{J}$ 1990;4:2528-32.

39. Greene CR, Holt PS. An improved chromatographic method for the separation of egg yolk IgG into subpopulation utilizing immobilized metal ion (Fe3+) affinity chromatography. J Immunol Methods 1997; 209:155-64.

40. Margni RA. Inmunología e inmunoquímica. 5a ed. Buenos Aires: Editorial Médica Panamericana: 1996.

41. Leslie GA, Clem LW. Chicken immunoglobulins: biological half-lives and normal adult serum concentrations of IgM and IgY. Proc Soc Exp Biol Med 1970;134:195-8

42. Schwarzkopf C, Staak C, Behn I, Erhard M. Immunisation. In: Schade R, Behn I, Erhard M, Hlinak A, Staak C, editors. Chicken egg yolk antibodies, production and application. IgY-Technology. Berlin:springer; 2001. p.25-64.

43. Ermeling B, Steffen E, Fish R, Hook R. Evaluation of subcutaneous chambers as alternative to conventional methods of antibody production in chickens. Lab Anim Sci 1992;42:402-7.

44. Rangel LE, Perera G, Lassala A, Zarco LA. Desarrollo de un método de radioinmunoanálisis para cortisol, utilizando anticuerpos obtenidos y purificados de la 
yema de huevo de gallinas inmunizadas. Vet Mex 1999;30:289-95.

45. Shin NR, Choi IS, Kim JM, Hur W, Yoo HS. Effective methods for the production of immunoglobulin $Y$ using immunogens of Bordetella bronchiseptica, Pasteurella multocida and Actinobacillus pleuropneumoniae. J Vet Sci 2002;3:47-57.

46. Leenaars PP, Hendriksen CF, De Leeuw WA, Carat F, Delahaut P, Fisher R et al. The production of polyclonal antibodies in laboratory animals. The report and recommendation of ECVAM workshop 35. Altern Lab Anim 1999;27:79-102.

47. Erhard M, Schade R. Short introduction to hens' humoral immune system. In: Schade R, Behn I, Erhard M, Hlinak A, Staak C, editors. Chicken egg yolk antibodies, production and application. IgY-Technology. Berlin:springer; 2001. p.1-8.

48. Yolken RH, Leister F, Wee SB, Miskuff R, Vonderfecht S. Antibodies to rotaviruses in chickens eggs: A potential source of antiviral immunoglobulins suitable for human consumption. Pediatrics 1988; 81:291-5.

49. Bizhanov G, Vyshniauskis G. A comparison of three methods for extracting $\lg Y$ from the egg yolk of hens immunized with Sendai virus. Vet Res Commun 2000; 24:103-13.

50. Wallmann J, Staak C, Luge E. Einfache methode zur isolierung von immunoglobulin $(Y)$ aus eiern immunisierter hühner "A simple method for the isolation of immunoglobulin $(Y)$ from the eggs of immunized hens". $J$ Vet Med B Infect Dis Vet Public Health 1990;37:31720.

51. O'Farrelly C, Branton D, Wanke CA. Oral ingestion of egg yolk immunoglobulin from hens immunized with an enterotoxigenic Escherichia coli strain prevents diarrhea in rabbits challenged with the same strain. Infect Immun 1992;60:2593-7.

52. Behn II, Hommel U, Oertel M, Hauschildt S. Kinetics of $\mathrm{lg} Y$ formation after immunisation of hens with different protein antigens. ALTEX 1996;13:18-21.

53. Camenisch G, Tini M, Chilov D, Kvietikova I, Srinivas $\mathrm{V}$, Caro J, et al. General applicability of $\lg Y$ immunoglobulins raised against the hypoxia-inducible factor $1 \alpha$. FASEB J 1999;13:81-8.

54. Pinto J. Obtención de anticuerpos policlonales en huevos de gallina dirigidos contra Parvovirus canino (tesis). Bogotá DC: Pontificia Universidad Javeriana; 2001.

55. Penttila IM, Voutilainen E, Laitinen $\mathbf{P}$, Juutilainen P. Comparison of different analytical and precipitation methods for direct estimation of serum high-density lipoprotein cholesterol. Scand J Clin Lab Invest 1981; 41:353-60.

56. Culliford BJ. Precipitin reactions in forensic problems. A new method for precipitin reactions on forensic blood, semen and saliva stains. Nature 1964;201:1092-4. 